\title{
A CONTRATAÇÃo diRETA NA ADMINISTRAÇÃO PÚBliCA EM ÉPOCAS DE CALAMIDADE PÚBLICA
}

\section{ARTIGO ORIGINAL}

LIMA, Raphael Silva de ${ }^{1}$

PEREIRA, Damiane de Souza ${ }^{2}$

NUNES, Victor Hugo da Silva ${ }^{3}$

LIMA, Raphael Silva de. PEREIRA, Damiane de Souza. NUNES, Victor Hugo da Silva. A contratação direta na administração pública em épocas de calamidade pública. Revista Científica Multidisciplinar Núcleo do Conhecimento. Ano 05, Ed. 05, Vol. 10, pp. 116-124. Maio de 2020. ISSN: 2448-0959, Link de acesso:

\section{RESUMO}

O presente trabalho tem por objetivo um estudo acerca da possibilidade das contratações diretas na Administração Pública durante estado de emergência ou calamidade pública, destacando que a contratação direta não é abrigo para uma livre atuação do gestor público, pelo contrário, deve estar vinculada a Lei de Licitações e ao dever de probidade com a coisa pública, mesmo em situações de calamidade. Conforme disposto no art. 37, XXI, da Constituição Federal em vigor, todas as compras realizadas pela Administração Pública devem passar pelo devido processo licitatório. No entanto, em emergência ou calamidade, pode-se contratar sem necessidade de licitação prévia. Desta forma, o que se pretende é delimitar, através de pesquisa bibliográfica, utilizando o método exploratório, os requisitos para atuação do administrador público e os fundamentos constitucionais e infraconstitucionais que

\footnotetext{
${ }^{1}$ Aluno de Bacharelado em Administração Pública.

${ }^{2}$ Aluna de Bacharelado em Administração Pública.

${ }^{3}$ Aluno de Bacharelado em Administração Pública.
} 
devem nortear as contratações diretas pela Administração Pública nos referidos casos.

Palavras-Chaves: Administração Pública, licitações, situações de calamidade e emergência, contratação direta.

\section{INTRODUÇÃO}

Com a intenção de promover a igualdade entre os concorrentes na contratação por parte da Administração Pública, a CRFB de 1988 trouxe em seu bojo a obrigatoriedade de licitar, excepcionando hipóteses legais para que a contratação pode ser realizada de forma direta, dispensando a realização de certame licitatório de forma a atender o máximo interesse público e priorizando a celeridade.

Assim, a própria Lei no 8.666/93 traz em sua redação a possibilidade de dispensa de licitação para situações de emergência ou de calamidade pública, em que estejam evidenciadas as possibilidades de danos a pessoas, obras, serviços e equipamentos, conforme inteligência extraída da leitura do art. 24 , IV da LLCP. No entanto, contratos celebrados nesses períodos não podem ser prolongados, devendo vigorar por até 180 dias, sem a possibilidade de prorrogação.

Deve-se, no entanto, vislumbrar que situações de emergência e/ou calamidade podem durar mais de 180 dias, o que instala a celeuma diante da impossibilidade jurídica da prorrogação do contrato, forçando ao gestor público a tomada de decisão de celebração de um novo contrato ou a realização de um processo licitatório de forma a atender a necessidade de contratação. 


\section{DESENVOLVIMENTO}

\subsection{LICITAÇÃO - CONCEITO, PREVISÃO LEGAL E PRINCÍPIOS NORTEADORES}

Licitação é procedimento administrativo unilateral vinculado quanto a forma quanto a forma e discricionário quanto ao objeto para a escolha do interessado em contratar com a Administração Pública pela melhor oferta de preços.

Segundo DI PIETRO (2018, p. 462) licitação é procedimento administrativo no qual entes públicos abrem a todos os interessados, que atendam aos requisitos do instrumento convocatório, a possibilidade de apresentarem propostas para celebração de contrato com a Administração Pública.

Licitação é definida como procedimento por se tratar de atos e fatos da Administração e do licitante, onde ambos cooperam para formar vontade contratual.

A definição de JUSTEN FILHO (2016, p. 546):

A licitação é um procedimento administrativo disciplinado por lei e por um ato administrativo prévio, que determina critérios objetivos visando a seleção da proposta de contratação mais vantajosa e a promoção do desenvolvimento nacional sustentável, com observância do princípio da isonomia, conduzido por um órgão dotado de competência específica.

Ainda, segundo SILVA (2004, p. 846), licitação vem do latim licitatio ou licitari e possui significado do ato de licitar ou fazer preço sobre coisa posta em leilão ou venda.

Assim, pode-se depreender dos conceitos expostos que licitação é procedimento administrativo para contratação quem oferece seus bens ou serviços em um concurso público.

Licitações são normatizadas pelo diploma legal, estando previstas na Carta Maior de 1988, em seu art. 37. Ainda, encontra-se a regulamentação da previsão constitucional 
na Lei no 8.666 de 1993 (Lei de Licitações e Contratos Públicos - LLCP), na Lei no 10.520 de 2002 (que dispõe sobre pregões eletrônicos), e ainda a Lei no 12.462 de 2011 (que instituiu o Regime Diferenciado de Contratações Públicas - RDC).

Segundo MEIRELLES (2003, p. 265), os princípios que norteiam as licitações são o princípio de procedimento formal, o princípio da publicidade dos atos administrativos públicos, o princípio da isonomia entre os licitantes, o princípio do sigilo das propostas, o princípio de vinculação ao instrumento convocatório do certame, princípio do julgamento objetivo e princípio da adjudicação compulsória. Além de, obviamente os princípios que devem revestir todo ato administrativo público, como a legalidade, impessoalidade, moralidade, publicidade e eficiência.

\subsection{CONTRATAÇÃO DIRETA - DISPENSA OU INEXIGIBILIDADE DE LICITAÇÃO}

A licitação é regra para a Administração Pública para a compra de produtos e contratação de bens e serviços. No entanto, há exceções a regra.

Em alguns casos a licitação é dispensada, dispensável ou inexigível. Cada modalidade dessa apresenta aspectos que justificam sua aplicabilidade, todas previstas no ordenamento.

No caso de dispensa, a licitação é possível, por existirem competidores, mas não é obrigatória, segundo se extrai da leitura do art. 17 da Lei no 8.666/93 (licitação dispensada) e corresponde a situação onde o gestor público está dispensado de licitar.

O art. 24 da Lei 8.666/93 diz respeito à licitação dispensável, que compreende situações onde existem suficiente e necessária motivação para dispensar a licitação de forma a imprimir celeridade a contratação. O referido artigo contém um rol taxativo que apontam as hipóteses restritas onde é possível dispensar a licitação. 
As hipóteses de inexigibilidade de licitação, prevista pelo art. 25 da Lei ํㅜ 8.666/93, que concerne em não existência de concorrência, é afastada a realização do procedimento licitatório, sendo esse impossível de ser realizado.

A licitação dispensável é a forma de contratação direta pela a Administração Pública, prevista no art. 24 da LLCP, atendidos os requisitos de pequeno valor da contratação, situações excepcionais, objeto a ser contratado e da pessoa a ser contratada.

Entre as hipóteses de licitação dispensável está a do inciso IV do art. 24 da LLCP, que prevê a dispensabilidade em casos de emergência ou de calamidade pública, quando comprovada a existência de urgência de atendimento com risco de danos a pessoas, equipamentos e bens públicos ou particulares, pelo prazo de 180 dias, vedada a prorrogação da contratação.

A Administração Pública deve, no entanto, comprovar que todas as medidas foram tomadas para evitar o quadro de emergência, sob pena de omissão e apuração de responsabilidades, deixando evidente que a falta da contratação nessas circunstâncias, provocaria dano ainda maior a pessoas, bens e interesses.

Portanto, o administrador público, pautado nos princípios gerais e legais da Administração Pública, principalmente, e destacamos, o de razoabilidade e proporcionalidade, deve adotar as medidas pertinentes a evitar os danos, celebrando o contrato emergencial.

Impende destacar que a LLCP não guarda uma definição do que seria emergência ou calamidade, o que acaba por atribuir ao gestor uma incerteza no trato com a situação, o que acaba por ser objeto de estudo de juristas e administradores públicos, de forma a sanear a controversa existente.

\subsection{EMERGÊNCIA - CONCEITO}

JUSTEN FILHO (2010, p. 238-240) assevera que a configuração da situação emergencial depende de uma circunstância fática em que a utilização do moroso certame licitatório implicaria em gravoso dano ao interesse público. 
Assim, depende do gestor público a identificação de uma situação por ele tida como grave e a realização de nexo com o interesse público, afastando assim a exigibilidade de licitação. Sendo assim, o apontamento de emergência não pode ser dado pelo senso comum, mas deve estar atrelado a previsão legal.

O art. 24, em seu rol taxativo, não aponta situações de dispensabilidade de licitação, e sim, do dever de contratar sem realização de licitação. Destacando que são condições em que pode haver prejuízos insanáveis na não realização da contratação, em priorização do procedimento licitatório. Há urgência na execução. Portanto, há urgência em contratar.

O Decreto ํㅜ 7.257 de 2010 dispõe sobre o Sistema Nacional de Defesa Civil, e prevê o reconhecimento de situação de emergência ou calamidade pública nas hipóteses de desastres, ocasião em que eventos adversos naturais ou provocados cause danos humanos, materiais ou ambientais, bem como prejuízos econômicos, ainda, disserta que situação de emergência é aquela situação anormal, causada por desastres, que implica em uma dificuldade de resposta do poder público do ente atingido, trata também da calamidade pública.

Assim, a situação de emergência pode ser descrita como evento imprevisível que provoca danos humanos de forma anormal, gerando dificuldade ao gestor público em responder de forma satisfatória e eficiente para salvaguardar pessoas, bens e patrimônios.

\subsection{CALAMIDADE PÚBLICA - CONCEITO}

O Decreto o 7.257 de 2010 prevê que situação de calamidade pública é situação anormal, provocada por desastres, causando danos e prejuízos que compromete substancialmente a resposta do poder público atingido.

A letra fria da lei destaca que a calamidade pública é estado grave, mas ainda se pode apontar uma dificuldade do legislador em definir de forma eficiente o que cada estado demanda do gestor público, para que esse de forma fácil, identifique e possa agir de 
acordo com a necessidade de resposta. No entanto, um ponto em comum é a imprevisibilidade do evento danoso.

MEIRELLES (1999, p. 98) preconiza que calamidade é uma situação de anormalidade decorrente de fatos da natureza, tais como, inundações e vendavais devastadores, epidemias letais, ou outros eventos que afetem profundamente a segurança, a saúde pública, o transporte coletivo, o trabalho em geral etc.

\subsection{PRORROGAÇÃO DE CONTRATOS EMERGENCIAIS}

O art. 24 da LLCP é claro na vedação da prorrogação dos contratos celebrados em situação emergencial ou de calamidade pública. Alguns gestores, diante dessa vedação, por ocasião do cumprimento dos 180 dias, omitem-se e agem como se o prazo não tivesse atingido seu limite.

Discute-se que o legislador se equivocou a utilizar o termo prorrogação, devendo ter utilizado o termo renovação.

MEIRELLES (1999, p. 130) salienta que prorrogação implica em prolongamento da vigência do contrato além do prazo inicial, nas mesmas condições anteriores, já a renovação implicaria na inovação no todo ou em parte do contrato, mantido, porém, o objeto inicial, para continuidade da execução. Assim, na renovação surgiria a possibilidade de recontratação direta com o atual contratado.

Na prática, no entanto, o prazo de 180 dias comumente não é suficiente para concluir serviços ou obras contratadas urgentemente. Seja em razão de excesso de chuvas, falta de materiais ou produtos, alterações de projeto etc.

Assim, o gestor público se vê impedido, ainda que perdure a situação de emergência ou a calamidade pública, de prolongar o contrato avençado emergencialmente. No entanto, não veda a celebração de novo contrato com a empresa contratada, enquanto durar o quadro. 
Não se deve deixar de lembrar que a regra é a realização do procedimento de licitação e que a legislação prevê a exceção nos casos de real urgência.

Em 2020, diante da declaração pela Organização Mundial de Saúde (OMS) de quadro pandêmico do novo coronavírus (SARs-Cov-2 ou COVID-19), através do Decreto Legislativo n 6 de 2020, o Brasil reconheceu a ocorrência de estado de calamidade pública, nos termos da solicitação enviada ao Congresso Nacional pelo Presidente da República Jair Bolsonaro, isso implica dizer que medidas de restrições de circulação de pessoas, créditos suplementares para socorro aos Estados e pessoas, além de contratações de forma direta, sem a necessidade de licitação, poderiam ser tomadas.

Impende dizer que durante a pandemia a necessidade de insumos básicos de saúde, equipamentos de proteção individuais (EPIs) e contratação de pessoal técnico não pode depender de um procedimento licitatório que demanda tempo e aplicação de recursos, que podem, em uma crise, ter aplicação que atinja o interesse público.

\section{CONCLUSÃO}

Da lei surge a obrigatoriedade em licitar, e estando o gestor público vinculado, seja pela legalidade ou a isonomia, a executar o procedimento licitatório para toda e qualquer compra ou obra que se faça necessária, surgem as possibilidades de exceção legal a essa obrigatoriedade.

Diante de preço exíguo de bem ou serviço, um evento calamitoso ou de emergência, ou da ausência de concorrentes, o administrador público adentra na exceção da obrigatoriedade da licitação.

O art. 24 da LLCP prevê essas hipóteses em rol taxativo, e assevera condições para que esses contratos sejam celebrados e possam existir. Assim, resta evidenciada a hipótese de licitação dispensável, de forma a atingir o melhor interesse público e salvaguardar pessoas, equipamentos, bens públicos ou privados etc.

A licitação dispensável impõe detida análise da condição para sua existência, já que é controvertido o reconhecimento de estado de emergência ou calamidade pública. 
Desta forma, o gestor público precisa explorar a situação fática de forma a encontrar requisitos que permitam sua delimitação, a saber, a existência de situação adversa que não foi gerada em razão de desídia da Administração Pública, a urgência ser real e efetiva, justificar a necessidade daquele serviço ou produto de forma a não paralisar a Administração Pública e acarretar danos ao interesse público, dar publicidade aos atos, além de justificar a escolha daquele fornecedor ou executante etc.

Não é permitido prorrogar contratos emergenciais celebrados pela Administração Pública após a sua duração legal de 180 dias, não sendo, no entanto, vedada a contratação sucessiva pelo período que durar a urgência ou calamidade.

Apesar de discricionária ao administrador público a contratação em situação de emergência ou de calamidade pública, não se pode olvidar estar este vinculado legalmente as diretrizes do permissivo legal.

\section{REFERÊNCIAS}

BRASIL. Constituição da República Federativa do Brasil de 1988. Disponível em: http://www.planalto.gov.br/ccivil_03/constituicao/constituicao.htm. Acessado em 20/04/2020.

- Lei no 8.666 de 21 de junho de 1993. Disponível em: http://www.planalto.gov.br/ccivil_03/leis//8666cons.htm. Acessado em 20/04/2020.

, Lei $\mathrm{n}^{\circ} 10.520$ de 17 de julho de 2002. Disponível em: http://www.planalto.gov.br/ccivil_03/LEIS/2002/L10520.htm. Acessado em: 20/04/2020.

- Decreto no 7.257 de 4 de agosto de 2010. Disponível em: http://www.planalto.gov.br/ccivil_03/_Ato2007-2010/2010/Decreto/D7257.htm. Acessado em: 20/04/2020. 
- Lei $\mathrm{n}^{\circ} 12.462$ de 4 de agosto de 2011. Disponível em: http://www.planalto.gov.br/ccivil_03/_Ato2011-2014/2011/Lei/L12462.htm. Acessado em: 20/04/2020.

. Decreto Legislativo o 6 de 20 de março de 2020. Disponível em: http://www.planalto.gov.br/ccivil_03/portaria/DLG6-2020.htm. Acessado em: 20/04/2020.

DI PIETRO, Maria Sylvia Zanella. Direito Administrativo. 31. ed. rev. atual. e ampl.Rio de Janeiro: Forense, 2018.

JUSTEN FILHO, Marçal. Curso de Direito Administrativo (livro eletrônico). 4. ed. - São Paulo: Editora Revista dos Tribunais, 2016.

MEIRELLES, Hely Lopes. Licitações e contrato administrativo. 12. ed. São Paulo: Malheiros, 1999.

SILVA, De Plácido e. Vocabulário Jurídico. Atualizadores: Nagib Slaibu Filho e Glaucia Carvalho. 25. ed., Rio de Janeiro: Forense. 2004.

Enviado: Maio, 2020.

Aprovado: Maio, 2020. 